\title{
IMAGES IN GASTROENTEROLOGY
}

\section{lleocolonic Intussusception: An uncommon Finding on Colonoscopy}

\author{
Pranav Kumar Mandal, Usha Goenka, Pranav Kumar Mondal, Enam Murshed Khan, \\ Madhuchanda Kar, Mahesh Kumar Goenka
}

Institute of Gastroenterology, Apollo Gleneagles Hospital, Kolkata, India

A 64-yr-male presented with blood mixed stool, intermittent crampy abdominal pain and significant weight loss of 3 months duration. Examination revealed pallor, pedal edema with left axillary lymphadenopathy. Colonoscopy showed multiple nodules and ulceration all over colon with intussusception of ileum from ileocecal valve (Figure 1). CT scan of abdomen revealed extensive retroperitoneal lymphadenopathy, diffuse thickening of gastric, intestinal and rectal wall with large segment ileocolic intussusception (Figure 2). Gastroscopy showed ulceronodular lesions in the stomach. Gastric biopsy showed lymph epithelial lesions characteristics of mucosa-associated lymphoid tissue (MALT) lymphoma (Figure 3). Immunohistochemistry was positive for CD 20(Figure 4) and BCL 2 and negative for CD 3, CD

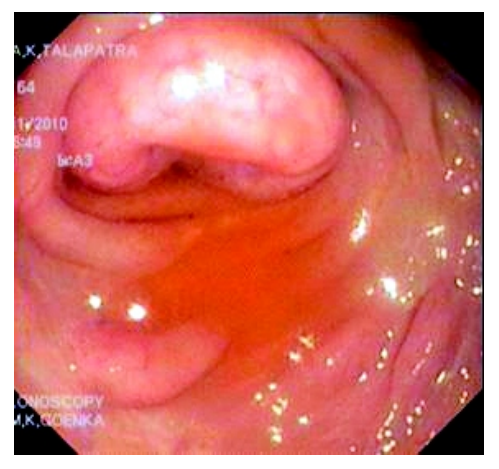

Figure 1: Colonoscopy showing intussusception of ileum from ileocecal valve

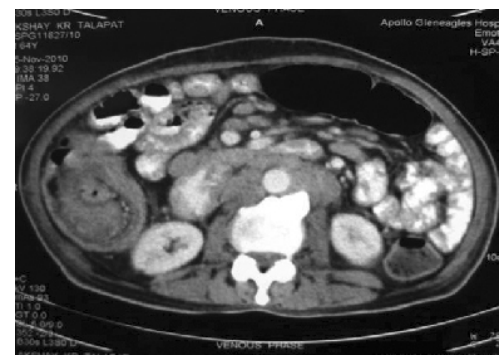

Figure 2: CT scan of abdomen showing retroperitoneal lymphadenopathy, diffuse thickening of intestinal wall with large segment ileocolic intussusception

\section{5, CD 10 and cyclin D1.}

Intussusception is an "internal prolapse" of the bowel, that leads to obstruction and compromise of mesenteric blood flow and the potential for ischemia of the bowel wall.[1] This occurs when a mass or lead point in the bowel (intussusceptum) is pulled forward by normal peristalsis, with resultant telescoping of the bowel wall (intussuscipiens).[2] In adults, intussusception is rare and accounts for 1 to 5 percent of bowel obstruction.[1] Adult intussusception commonly involves a distinct pathologic lead point, which is malignant in over half of the cases unlike benign etiology in cases of

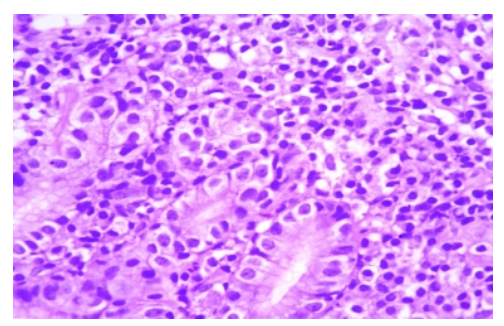

Figure 3: Gastric biopsy showing lymph epithelial lesions characteristics of mucosa-associated lymphoid tissue (MALT) lymphoma.

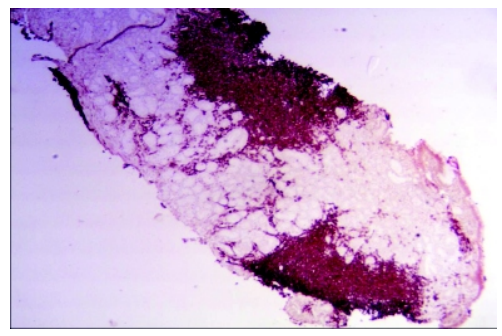

Figure 4: Immunohistochemistry of gastric biopsy positive for CD 20.

pediatric intussusception.[1,3] In our case, etiology was MALT associated B cell lymphoma involving stomach, small bowel and colon. Moreover, there is evidence of transformation into large B cell lymphoma with involvement of lymph nodes. Usually, the disease involves a single primary site; however, multiple sites within the GI tract may be involved like the index case.

Intussusceptions are classified by location (Entero-enteric, colo-colic, ileo-colic and ileo-cecal). A "target sign" is seen on CT on perpendicular view, while the intussusception will appear as a sausage shaped mass when the CT beam is parallel to the longitudinal axis.[2]

\section{References}

1. Marinis A, Yiallourou A, Samanides L, Dafnios N, Anastasopoulos G Vassiliou I, Theodosopoulos T. Intussus-ception of the bowel in adults: a review. World J Gastroenterol 2009;15:407-11.

2. Gayer G, Zissin R, Apter S, Papa M, Hertz M. Pictorial review: adult intussusception - a CT diagnosis. Br J Radiol 2002;75:185-90.

3. Nagorney DM, Sarr MG, McIlrath DC. Surgical manage-ment of intussusception in the adult. Ann Surg 1981;193:230-6.

Source of support: Nil; Conflict of interest: none declared

Reprints requests and correspondence:

Dr. Mahesh K Goenka

Director \& Head, Institute of Gastroenterology

Apollo Gleneagles Hospitals, Kolkata

58 Canal Circular Road, Kolkata 700054

e-mail-mkgkolkata@gmail.com, 